\title{
SEISMOLOGY MICROFICHE PUBLICATIONS FROM THE CALTECH ARCHIVES
}

\section{EDITED By}

\author{
J. R. Goodstein, H. Kanamori, And W. H. K. Lee
}

In order to preserve important seismological documents and make them available inexpensively, the California Institute of Technology Archives (with partial financial support from the U.S. Geological Survey) has initiated seismology microfiche publications. The microfiche (Mf.) format is diazo positive film measuring 105 by $148 \mathrm{~mm}$ ( 4 " by $6^{\prime \prime}$ size). Each microfiche contains 70 frames or less at a maximum reduction of $24 \times$. At present, three series are available to the public at cost of reproduction and handling:

\section{SERIES I}

(a) Bulletin of the CIT Seismological Laboratory, Pasadena and Auxiliary Stations, 1931-1968.

Monthly bulletins covering teleseismic shocks registered at the Seismological Laboratory at Pasadena and at auxiliary stations at Mount Wilson, Riverside, Santa Barbara, La Jolla, and Tinemaha and Haiwee (in the Owens Valley). Bulletin gives details of measurements for local and distant earthquakes in standard international form. Reports compiled by C. F. Richter and others. Additional stations added to southern California regional network later on. Title varies; changed to Preliminary Bulletin on January 1, 1957.

(b) Provisional Readings at Pasadena (and auxiliary stations as noted), 19661974; changes title to Airletters, June 1, 1974-April, 1979.

(c) Station Clock Corrections

Pasadena, January 1931-January 1973

China Lake, September 1951-August 1975

Mt. Wilson, November 1951-September 1970

Riverside, November 1951-April 1979

Palomar, December 1951-April 1979

Santa Barbara, December 1951-April 1979

Tinemaha, December 1951-April 1979

Woody, August 1952-August 1970

Fort Tejon, November 1952-August 1970

Barrett, February 1952-April 1979

Isabella, January 1954-April 1967

Hayfield, January 1956-April 1979

El Centro, January 1957-August 1970

Goldstone, November 1961-February 1969

Live Station, September 23-25, 1963

Cotton, October 1965-April 1979

Sawmill, March 1966-March 1976

Rio Hardy, April 1969-January 1973

Bahia de Los Angeles, December 1971-August 1973

Guaymas, March 1972-July 1973 
Obsidian Butte, May 1972-July 1972

Caborca, Sonora, July 1972-August 1973

La Paz, July 1972-August 1973

Topolobampo, August 1972-August 1973

Camp Pendleton, January 1975-April 1979

106-Mf. $\$ 57.00$

SERIES II

International Seismological Summary, 1918-1942

Beno Gutenberg's annotated copy of the ISS, Turner, H. H. et al. (1923-1952). Only pages containing Gutenberg's penciled-in corrections and revisions for epicenter, origin time, and focal depth of shocks are included.

72-Mf. $\$ 40.00$

SERIES III

Gutenberg-Richter Notepads, 1904-1958

All the known unpublished original worksheets for Seismicity of the Earth (1954), including calculations and data relating to the magnitude scales employed by Gutenberg and Richter in their catalog.

116-Mf. with index $\$ 64.00$

Each Series can be ordered separately by writing to:

\author{
Attention: Dr. J. R. Goodstein \\ Institute Archives \\ California Institute of Technology \\ Pasadena, CA 91125, U.S.A.
}

Payment must follow within 30 days of receipt of invoice; discounts for cash with order 5 per cent and free postage. Postage (air mail overseas) is added.

Author affiliations:

\author{
J. R. Goodstein \\ Institute Archives \\ California Institute of Technology \\ Pasadena, CA 91125 \\ H. Kanamori \\ Seismological Laboratory \\ California Institute of Technology \\ Pasadena, CA 91125 \\ W. H. K. Lee \\ Office of Earthquake Studies \\ U. S. Geological Survey \\ Menlo Park, CA 94025
}

